\title{
Demographic and Commercial Environments and Building Control Customer Services
}

\author{
Peter Hope \\ Education, Research and Industry, the Queensland Building and Construction Commission, 299 Montague Road, West End, QLD 4101, \\ Australia
}

\begin{abstract}
A simple and cost effective business analytics schema developed in this study provides a basis for observing how demographic and commercial environmental impacts affect building control customer services. In order to overlay environmental impacts onto building control services, schematic mapping of resource distributions and services were plotted according to corporate jurisdiction, corporate virtues and customer type characteristics. Quantitative and qualitative surveys were conducted on corporate staff and material resources, business performance measures and targets, building control service manager observations and demographic and commercial environments. Results from this research provide a single view corporate map of people, material resources, and service performance in relation to customer characteristics, while reaching out to better understand the building control customer experience, general public expectation and market influences. In this regard, this research can provide a foundation for realising corporate virtue aspirations.
\end{abstract}

\section{Introduction}

This paper presents a new approach stemming from a business analytics case study on how demographic and commercial environments affect corporate services. The research methods referred to in this paper offer a low impact, cost effective, quick and easy approach to business analytics.

The purpose of the research project is to identify how building control services can more effectively respond to changes in demographic and commercial environments, service resource distribution realities and performance indicators and identified corporate virtue aspirations and benefits to customers, in the process.

A business analytics schema developed in this study relies on available publications and corporate data. Expert advice from industry experts provided insights into demographic and commercial forecasts [1, 2]. While expert advice from senior building control managers enabled a better understanding of business operational matters.

Further, building control service managers were interviewed about their observations of their service teams in relation to set criteria such as: workload, team ability, material resources, service quality, performance, output targets, customer feedback and overall performance.

The results of this research offer the Queensland Building and Construction Commission (QBCC, Australia) insights on demographic and commercial influences concerned with building control customer services. Further, a conceptual framework has been developed for mapping resource distributions, performance measures, and corporate virtue aspirations, upon which future research can be based.

\section{Background}

\subsection{The building control in Queensland}

The QBCC engages approximately 380 staff to provide approximately 72 services in a market that produced 90,759 residential construction contracts in 2014/15, of which approximately five percent of these dwellings were subject to building disputes between parties to the building contract. For example, 4,793 disputes were received by building control customer services in the 2014/15 year.

The QBCC provides award winning customer service standards, contemporary marketing, digital and media systems, building compliance and regulatory services, home warranty scheme insurance and other key corporate support services [3].

Building work standards in Queensland are governed by the Building Act 1975 (Qld), the Queensland Development Code, the National Construction Code of Australia (NCC) and Australian Standards, as called up in the NCC. All on-site construction requirements relating to building work are governed by the Queensland Building and Construction Act 1991 (Qld) which essentially evokes the jurisdiction of the QBCC $[4,5]$. 


\subsection{Corporate virtues}

Corporate virtues are aspirations for building control customer services [6] that refer to the QBCC vision to be recognised as the best and most respected regulatory service provider in Australia, its purpose for peace of mind and its core values which put customers first, unleash potential, to be courageous, to put ideals into action, empower people, provide a safe and healthy working environment, with an emphasis on the building control customer service value chain.

The quantity and efficiency of the building control are attributes of customer service performance reflected through the attainment of corporate virtues that support a vision which in turn is dependent on public expectation and the private building contract experience, which is subject to customer feedback [7].

Five main building control services are described as [7]:

a) Licensing services,

b) Compliance and enforcement,

c) Dispute prevention and resolution services,

d) Home warranty insurance, and

e) Information and education.

\subsection{Building control jurisdiction}

The QBCC $[3,6]$ regulates the building industry, stipulating remedies for defective building work, while providing support, education and advice for building contractors and consumers. Building control customer services in Queensland facilitate a balance between the interests of building owners and principle contractors through the regulation of domestic building contracts.

\subsection{Building contractor licencing}

Queensland maintains one of the widest ranges of building industry skilled trade practice registers in Australia. For example, there are 87 licence classes including: builder, trade contractor, plumber and fire protection license classes, all together constituting 85,627 licensed individuals [9].

To qualify for a licence, individuals must have prescribed qualifications, experience and business acumen $[3,9]$. In addition, the building industry depends on professional abilities such as: quality control, managerial, logistical and organisational skills, particularly in highly competitive environments $[10,11]$.

\subsection{Continuous professional development}

In Queensland, Continuous Professional Development (CPD) of licensed building contractors remains voluntary for the majority of licence types. However, it is likely that those practitioners most in need of CPD training “....are those least likely to become involved" [12].

While large building organisations apply building practices more efficiently and effectively, predominant issues of competency and the rate of building disputes concerning building control customer services lies with small building businesses [13, 14, 15, 16]. Further, building defects contribute to the cost and affordability of new housing $[10,14,15,17,18]$.

Extrapolating from Smith, et al., [11] reference to 800,000 properties in the state of Victoria, of which $110,000(13.7 \%)$ were subject to defective building work related claims the rate of building defects in the state of Queensland is somewhat lower (5.2\%). For example out of 90,933 building projects 4,793 building disputes were received by the QBCC in 2015 [4].

While the prospect of a five percent defect rate may not seem large in general terms, for the individual parties to the building contract the associated costs, time-loss and stress of building dispute, resolution process, and rectification work is most likely disappointing, undermining confidence, underpinning negative preconceptions and revealing inefficiencies.

Further, additional costs and resources resulting from building disputes are incurred by building control customer services including expert investigations [4]. Building dispute costs ultimately result as an investment overhead cost to new buildings $[10,14,16,17]$.

\subsection{Building disputes}

The Queensland residential building industry provides an important contribution to the State economy. However, a contentious issue is the cost of building disputes between parties to the building contract, predominantly over defective building work [10, 14, 15, 17, 18].

The estimated cost of resolving major contract construction disputes in Australia is between $\$ 560$ million and $\$ 840$ million per annum. By including avoidable costs such as associated opportunity and delay costs the total waste costs is approximately A $\$ 7$ billion annually [19]. However the cost of building disputes to small business, which is predominant in the residential sector of Queensland, remains unclear [20].

The government has emphasised the importance of small business as a driver of economic growth [21]. The Construction and Property Services Industry Skills Council (CPSISC) points out that, Construction is the second largest industry gross value-added contributor representing approximately 7.8 percent of the nations' GDP in trend terms $[21,22]$. However a concern is that the largest rate of small business insolvencies is associated with the Construction sector [16].

\subsection{Demographic and commercial environments}

Australian population growth trends are easing, at approximately 23,839,000 people. Household formation trends are aligned with population trends, at 8,685,000 new households. Household occupant size also remained steady at 2.74 persons, in Australian terms by 2015 estimates [2].

Stable monetary policy and strong financial systems of Australia provide a sound basis for open market competition and innovation [1]. Household and business service conditions appear to be improving, while there remains considerable uncertainty around the economic recovery [23]. 
Economic characteristics following the international 2008 financial crisis include: a stronger emphasis on the 'balance sheet', changing demographics and less extreme growth rates, etcetera [23].

Over the long term, population and economic growth are factors expected to drive residential and non-residential building activity, along with improvement in real income levels, demographic changes, the industry supply chain, employment growth, building floor sizes, and market expectations on quality produced [2].

Overseas investors are attracted to Australia because of its reliable legal system, clean air, and child education qualities [1]. Current economic transitions away from resource sector exports suppress economic drivers and foster investor caution, mitigating supply and therefore securing prices.

A disparity between property asset holders and market realities occurs as owners 'reluctant to sell at a loss' avoid selling during slow markets, which underpins the unaffordable housing phenomena. The result over time is a perception of rising property prices, in-between growth markets $[1,2]$.

Existing house prices in Brisbane, the capital city, were $\mathrm{A} \$ 505,000$ (up 7.4\%), while house rents were A $\$ 375$ per week (up 1.4\%), in Queensland by 2015 estimates [2].

Average floor area size of new houses remains at 257.8 per square metres. While average residential building costs are A $\$ 1,059$ per square meter, in Australian terms by 2015 estimates [2].

Owner-occupiers appear to be turning from detached housing aspirations to more affordable, better located multi-residential solutions, inflating activity and prices in the multi-residential-complex sector [2]. A shift from detached housing to multi-residential solutions appears to be the result [1].

Major building contracts such as civil or commercial development can be mapped in cycles of activity, but trends tend to be skewed by large single developments in unique locations [2]. Similarly, residential development (hotspots) in regional Queensland, following rapid growth in the resource sector, has slowed as populations migrate back to the capital city for work which has stimulated demand for, and development of housing in Brisbane.

However, building control customer services remain active despite building demand and supply interplays. Residential building disputes typically occur up to 6 years and 3 months following the building completion, in Queensland.

This duration represents the home warranty insurance period within which funds can be made available to rectify defective building work where the builder is unwilling or unable to take responsibility. Therefore building dispute activity can remain buoyant when building commencement trends slow [4].

The following schematic view of environmental influences and stages of new building activity in Queensland [Figure 1], derived from this study, enables discussion between stages of interest. For example, building control customer services are shown (in the fourth last stage) toward the bottom, but are 'triggered' at the Private Contract stage (five stages before) and in less than 0.008 percent of cases continues through to building control enforcement (709 directions to rectify issued; 2014/15).

\begin{tabular}{|c|c|c|}
\hline & QUEENSLAND & \\
\hline \multirow[t]{2}{*}{ Demographics } & Economy & Employment \\
\hline & ENVIRONMENT & \\
\hline \multirow[t]{2}{*}{ Demand } & Finance & Affordability \\
\hline & AMENITY & \\
\hline \multirow[t]{2}{*}{ Health } & Safety & Efficiency \\
\hline & NEW BUILDING & \\
\hline \multirow[t]{2}{*}{ Design } & Capacity & Standards \\
\hline & PRIVATE CONTRACT & \\
\hline \multirow[t]{2}{*}{ Documentation } & Peace of mind & Assets \\
\hline & CONSTRUCTION & \\
\hline \multirow[t]{2}{*}{ Certification } & Competency & Payment \\
\hline & COMPLETION & \\
\hline \multirow[t]{2}{*}{ Handover } & Compliance & Yield \\
\hline & WARRANTY & \\
\hline \multirow[t]{2}{*}{ Performance } & Responsibility & Costs \\
\hline & CONTROLS & \\
\hline \multirow[t]{2}{*}{ Mediation } & Enforcement & Insurance \\
\hline & THE PUBLIC INTEREST & \\
\hline \multirow[t]{2}{*}{ Awareness } & Confidence & Expectation \\
\hline & INFRASTRUCTURE & \\
\hline \multirow[t]{2}{*}{ Maintenance } & Life cycle & Sustainability \\
\hline & BEST PRACTICE & \\
\hline
\end{tabular}

Figure 1: The building control environment

\subsection{Building control customer services}

The QBCC provides a broad and diverse range of building control customer services through a 'one-stop-shop' public service. These services are franchised to nine customer service centres in major cities of all regional areas across the state of Queensland.

Consequently, in order to better understand the outcome of building control customer services from the customers' perspective, public expectation and the private building contract experience are considered to be two key aspects of building control services. Public expectation can be understood through a range of perspectives including: legislation and enforcement provisions, building standards, economic drivers, media reports, consumer surveys and inquiries and public uptake of the building control information.

\subsection{Building control resources}

To manage customer services, the QBCC receives income from building licensing and building warranty insurance provisions needed for resources such as: people, time, 
budget and technology.

While the economy grows and slows, on average building control revenue appears more static in the sense that public service income does not compound as businesses-for-profit models expect too.

Further, while building activity fluctuations occur, building control customer services appear more continuous. This on-going demand may in-part be due to a broad range of building control services and the home warranty insurance period referred to above.

Further to add to the costs of building control customer services, the evolution of new public technological applications drives a need for additional building control digital communication platforms that are needed over-and-above on-going public service costs (i.e. social media, digital app mechanisms, touch screen devices, 3-D printing of building components, BIM communication channels, free trade compliance standards, etcetera) [4].

\subsection{Business analytics schema}

The business analytics schema devised for this study is a sematic diagram displaying a map of corporate resource distributions (inputs, outputs and outcomes) concerning building control service groupings, according to customer type (public, private and internal corporate).

The business analytics approach applies readily available corporate measures such as the consolidated budget, the number of staff, the Organisational Chart and Key Performance Indicators (KPI), etcetera.

\subsection{Frontline services}

This study further considers the number and nature of frontline customer services as applied to building work, a central responsibility of the QBCC [3, 4]. Approximately 43 percent of 72 building control customer service teams have been surveyed, representing all building control 'frontline services'.

\subsection{The private building experience}

The private building experience refers to both parties to the domestic building contractual agreement, the building owner and the principle contractor. The private building experience can be understood through both their contractual process and the extent that they understand their responsibilities, form their expectations and the circumstances under which they may enter into dispute.

\subsection{Stages of the building contract process}

Three stages of the private building contract experience are: commencement, completion, and the following six year and three month home warranty insurance period.

These divisions enable overall service results to be 'distilled' down to five customer service orientations or characteristics which are:

a) Corporate services and business excellence (accountability), b) General public expectation and awareness services (confidence),

c) Building compliance services, during construction work (standards),

d) Services concerned with building completion, certification and approval (peace of mind), and

e) Building performance, disputes and rectification work (the contract warranty period).

The following schematic diagram [Figure 2] illustrates cycles of building control frontline services, from customer needs (catalysts) to building controls (compliance). These are 'cause and effect' relationships that turn the wheel of building control customer services clockwise in stages from the outside toward the inside, or vice versa. Connecting needs to services, the 'weakest link in the chain' analogy can be applied to these service cycles.

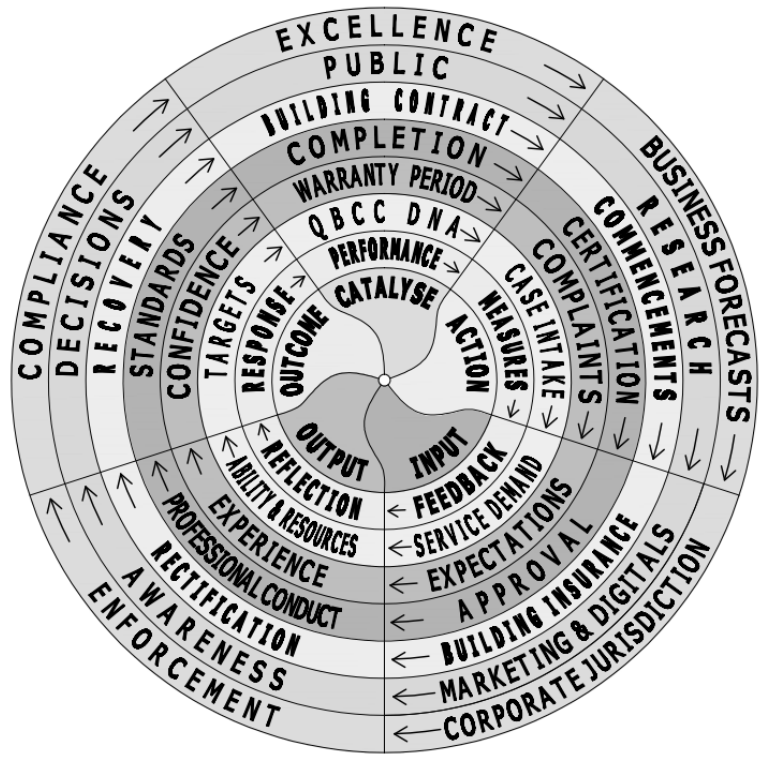

Figure 2: Building Control Service Flows

\section{The case study}

\subsection{Issues}

In order to better understand how building control customer services respond to demographic and commercial influences this case study explored a means of observing business 'hotspots' and 'risk spots', resource distributions, service performance measures, and the corporate environment from a customers' perspective by identifying customer types and aligning services accordingly.

Hotspots refer to customer services with high workloads, while risk-spots refer to those services with potential to mitigate future customer needs, through proactive activities.

Given the complexity and the extensive implications of the research question the contribution of this case study has been limited to developing and mapping a business analytics schema comprised of theoretical constructs and services associated with private and general public customers. While corporate customers form part of the perspective of this study, the focus is on 'frontline' customer services. 
The issues related to building control customer services are:

a) understanding corporate virtue aspirations,

b) understanding characteristics in common of building control customers services, or how they may differ,

c) understanding the performance of services,

d) understanding the people and material resources,

e) identifying channels for understanding general public expectation and private building experiences, and

f) understanding the effects of demographic and commercial factors.

\subsection{Breakdown}

The factors concerning this case study include:

-corporate vision, purpose and values (virtues),

-the building control jurisdiction,

-building control customers:

$\circ$ general public expectations,

$\circ$ private building experiences,

-workloads of building control customer services,

-corporate resource distributions,

-quality of building control customer services,

-performance validity of building control customer services,

-building control customer service target reliability,

-building control customer service feedback channels,

- overall performance of building control customer service groups, and

•new building commencement, compliance, disputes, and control trends.

\subsection{Available Information}

The QBCC Act 1991 (Qld.) provided parameters of building control jurisdiction to better define core corporate responsibilities for customer services prioritisation purposes.

QBCC 2015 Corporate Plan and an internal corporate 'DNA reference sheet' provided a current interpretation of building control customer service aspirations concerning corporate virtue or value aspirations [7].

Available government literature on demographic and economic trends provided social science insights into building control customer behaviour, looking forward [1, $2,23,24]$.

Building industry and property forecast 2015-2030 reports provided analytical summaries on the Queensland economic and demographic outlook to better understand current and future market drivers and behavioural trends $[1,2]$.

The QBCC People and Culture division provided 2015 data on staff numbers and designations enabling mapping of human resource distributions in terms of the type of building control customer group.

The QBCC consolidated budget 2014-15 provided accounts that enabled mapping of material resource distributions in terms of building control customer service groupings.

QBCC corporate publications, digital accounts and raw data provided an emphasis on key performance indicators in relation to under-measured aspects of building control services [3, 6, 7, 8, 9].

\subsection{Verification}

While available information provided insights into the corporate role and direction for building control customer services, key factors include new building market activity and social trends, the distribution of corporate people and material resources and KPI measures that enable analysis on building control service activities and under-measured services.

Expert observations were recorded and aggregated as a way of verifying conclusions drawn from available historical trends and theoretical information. This case study was limited to 'front-line' building control customer services which represent approximately 43 percent of all corporate services identified for mapping purposes.

Expert observations from managers of 31 building control customer services were interviewed for validation purposes. The survey interview technique needed to be easily understandable and quick to attend to for busy respondents.

\subsection{Constraints}

This research project began with a time constraint of approximately 10 weeks. Further, the research activities were conducted by one principle research officer who is familiar with the corporate business and has conducted related corporate research projects.

As this work had not been done before, it is inductive by nature. Therefore care had to be taken in the design, implementation and review of the methods.

The case study utilised available information to generate operational suppositions that could be verified by expert advice. Propositions were applied to developing the conceptual framework needed for the business analytics schema.

Indicative insights enabled recommendations on the need to prioritise customer service 'hotspots' and 'risk spots' with more targeted research probes based on the foundations of the conceptual framework.

It is envisaged that more targeted research can support hypotheses on building control customer service efficiencies, enabling deductive research validation over the medium to long term.

\subsection{Historical information}

Historical data needed to better understand factors and trends were derived from QBCC data. Raw data included:

-the number of mandatory insurance policies representing the number of commencements of detached house building and medium-rise 
residential dwellings and alterations and additions;

- the number of building complaints received; and

- the number of defective work rectification orders issued (directions).

Further insights were derived from previous corporate research reports concerning building inspector observations, case management costs and workload audits etcetera.

\subsection{Correlations}

In order to develop a basis for understanding the correlation between demographic and economic environmental impacts and building control customer services it was necessary to identify the type of customers, their relationship to building work, demographic and commercial environmental factors, along with building control customer service types.

While the business analytics conceptual framework encompassed all building control customer services, of the three relevant customer types: corporate (virtues), public (expectation) and private (experience), service teams predominantly concerned with the latter two customer types were investigated further through building control customer service manager observation interviews.

\subsection{Limitations}

To advance understanding of correlations between building control environmental factors, customers and services a business analytics schema was developed to enable mapping of building control customer service resources, performance and service outcomes through customer feedback channels.

The benefit of the business analytics schema is to provide a platform for mapping services to customers upon which corporate priorities can be determined.

However, cause and effect correlations of market forces, the private contracting experience and building control customer services are beyond the reach of this case study, which is intended to support on-going research, stemming from this study.

\subsection{Assumptions}

A conceptual framework (business analytics schema) formulated through heuristic insights $[25,26]$ provides a method of observing relevant factors, with a single view schematic diagram.

It assumes that common public perceptions of new building work processes may be generally inherent in private building owner expectations and consequently their underlying attitudes in building disputes. Similarly, private building contractor preconceptions about their contract responsibilities may limit communication, information transfer and dispute resolution efforts $[4,19]$.

The extent that general public expectations are in alignment with minimum building standards is outside the scope of this study, a question in need of additional research to inform awareness rising education services.

\subsection{Decisions}

The methods adopted in this case study provided an indicative understanding of building control customer service 'risk-spots' and 'hotspots' that suggests where resource distribution priorities are needed.

Further the business analytics schema provides 'a lens' through which building control services, with common customer types, can be grouped and analysed in terms of resource expenditure, service performance and customer service outcomes.

Insights and indicative results are substantiated by both corporate performance reports and anonymous expert customer service observations generalised into customer groupings to mitigate bias. However the conceptual framework can be considered a theoretical basis upon which more focused research is required.

\subsection{Protagonists}

The protagonists of this case study are building control customer services, represented by team managers, 'operating on the wheels of frontline customer services'. The service team performance is dependent on their legislative jurisdiction, corporate aspirations, and customer expectations.

\subsection{Dartboard survey}

The Dartboard survey [Figures 3] along with a multichoice questionnaire were designed to be presented to building control customer service managers (the protagonists) as part of an interview technique that ensured respondents received a uniform understanding of the context of the survey terminology to support validity.

The same interviewer consistently applied the interview survey methods to support reliability. Interview responses were anonymous and respondents were advised that their contributions were to be aggregated by customer type, mitigating the risk of bias. Further, interviewees were not privy to the results of other respondents, to avoid external influences.

Respondents were asked to mark a spot on the Dartboard survey as to whether each one of eight aspects: needs attention, are satisfactory or appear in great shape.

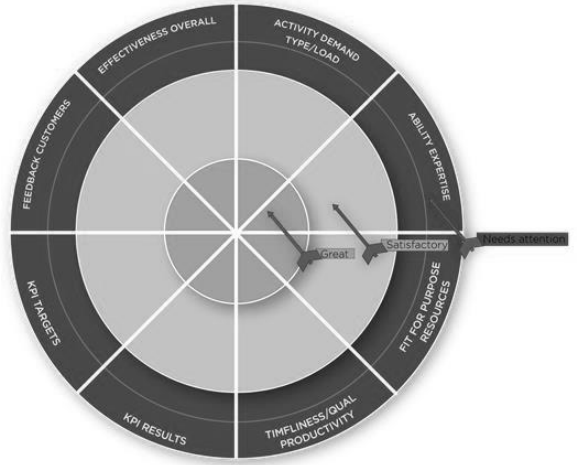

Figure 3: Dartboard survey and interview instrument

The aggregated Dartboard survey and interview results [Figure 4] for example, suggest that attention is needed on building control customer service demand 
activity (workload), material resources and performance measures. Conversely, service managers appear more than satisfied with staff ability and customer service feedback channels. Overall service effectiveness and quality appears satisfactory.

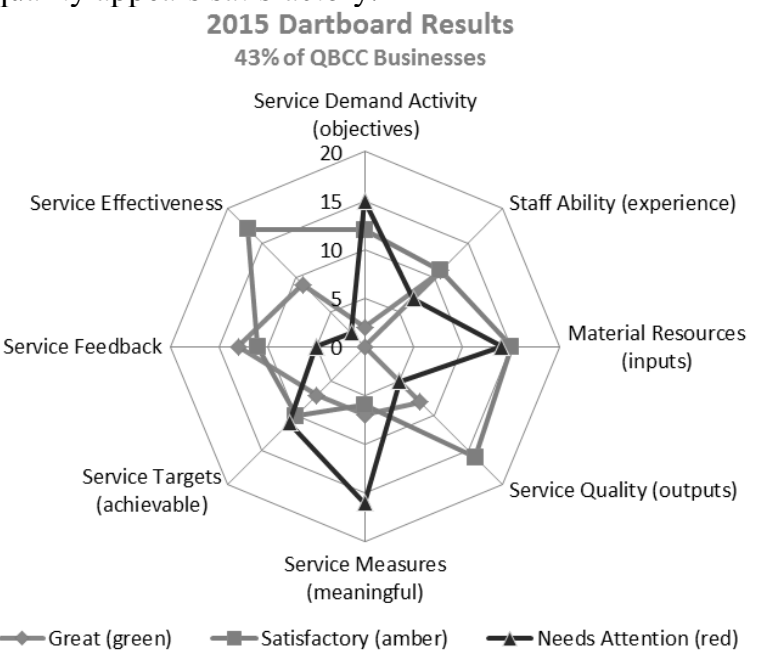

Figure 4: Dartboard survey and interview results

\subsection{Building control customer service manager interviews}

Generally, building control customer service managers were enthusiastic about their responses to the survey interview, once they understood that it would not take too much time. The interviewer provided an important function by contextualising the questions to enable quicker and more concise responses.

On an accompanying multi-choice questionnaire, respondents were able to select their service team predominant customer group and most important business resources, most referred to KPI measures and most sort after service results, most important service benefits and most important demographic and commercial environmental impacts.

\subsection{KPI survey}

The KPI survey plotted the frequency and spread of current KPI measures across 72 services, in an attempt to better understand what aspects of services were being measured and what was not. These results were compared with building control customer service manager observations to better understand the quality and application of current KPI measures and the practicality of service targets.

\subsection{Survey of resources}

The people and material resource distribution analysis mapped on the business analytics schema enabled an overview of corporate investment and resource distribution to building control and customer service benefit analysis. However, detailed analysis results on the efficiencies of customer service inputs, outputs and outcomes are beyond the scope of this preliminary case study.

\subsection{Conceptual framework}

Further the conceptual framework of the business analytics schema [Figure 5, below] provides a view of factors and customer service feedback channels along with aspects of corporate values.

\subsection{Approach}

Cause and effect relationships between market drivers, consumer behaviour, available resources, service abilities and workload pressures are complex multi-dimensional phenomena. The risk of increased building defects during periods of high building activity, as supply struggles to meet demand, along with customer demographic and behavioural variables can introduce a higher level of complexity to building control customer services and corporate resources. Considering the complex nature of the environment, this case study begins the process of building control customer service analysis rather than concludes it.

\subsection{Context}

In transition are: the 2014 corporate restructure, from the previous statutory authority to the current statutory commission; corporate communication channels from paper and telecommunication technologies to social media and digital administration platforms.

Further, amidst a climate of general economic transition $[23,27]$ and social adjustment experts refer to the 'new norm', characterised as slower more steady new building market activity growth [1, 2, 23].

\begin{tabular}{|c|c|c|c|}
\hline & \multicolumn{2}{|c|}{ Environmental Influences } & \\
\hline Public Customers & & & Private Customers \\
\hline Economic Aspect & \multicolumn{3}{|c|}{ Industry Activity Aspect } \\
\hline Demographic Aspect & & \multicolumn{2}{|c|}{ Skills and Supply Aspect } \\
\hline Health, Safety and Sustainability Aspect > & Regulatory Aspect & \multicolumn{2}{|c|}{$<$ Amenity and Performance Aspect } \\
\hline Confidence Aspect> & Quality Assurance Aspect & \multicolumn{2}{|c|}{$<$ Peace of Mind Aspect } \\
\hline \multirow{2}{*}{$\begin{array}{r}\text { Public Education and Expectation Channels }> \\
\text { Government and Commerce }>\end{array}$} & Feedback Aspect & \multicolumn{2}{|c|}{$<$ Building Owner and Principal Contractor Channels } \\
\hline & Resource Aspect & \multicolumn{2}{|c|}{$<$ Licensing and Insurance Provisions } \\
\hline
\end{tabular}

Figure 5: A conceptual framework 


\subsection{Consequences}

The consequences of not embarking on a series of orchestrated research probes into the extent that building control customer services are achieving the aspirations of corporate virtues are a matter of due diligence.

Efficient building control customer services can mitigate the recurrence of building defects and discourage frivolous building disputes. Investments in developing better building control customer services may need to be measured in terms of the corporate aspirations to achieve their stated virtues.

As the organisation aspires to be courageous, unleash potential and empower people, it runs a risk of adverse reactions if building control customer service teams continue to be frustrated by avoidable limitations.

\subsection{Alternatives}

The alternative to conducting systematic research on the investment in, and benefit of, building control customer services may be to continue to respond to transitions from the 'business as usual' model to more prescribed objectives, relying on heuristic observations as they become apparent, assuming assumptions are reflective of the underlying realities.

\section{Conclusions}

This inductive research is dependent on available information and historical data to develop insights into building control customer service conventions from past performance. The conceptual framework provides insights through mapping building control customer services.

Further, the research explores current customer service efficiencies, performance standardisation and the potential to realise corporate virtues. While the results can form a basis for prioritising future more targeted research.

Transitions reflected in the economy, public expectation, confidence in private new building and uptake of building control services present opportunities for the QBCC to consolidate change, reflect on core business objectives, with finite resources and prioritise applications in the pubic best interest.

Demographic and commercial influences can be seen through a business analytics view of general public and private customers that subscribe to building control services. To better enable prioritisation of limited resources in the public best interest, an understanding of customer types through their characteristics is informative, such as:

1) public expectation of, and confidence in, new building investment;

2) private building experience of both, the owner and principle contractor; and

3) corporate service team performance and accountability.

With the focus on building control jurisdiction, and corporate values, applied to prioritised services in the public best interest, best practice can be determined amidst an environment of economic transition.

\subsection{Survey Instruments}

The Dartboard survey instrument, applied to frontline managers, covers key business performance elements such as demand, capacity and performance which are generic and useful in reviewing key strategic objectives (such as customer satisfaction).

In application, the Dartboard survey stimulated engagement as frontline managers considered service capability, capacity and performance in relation to demand with the understanding that their responses would be aggregated into results associated with customer groupings, rather than their individual businesses.

The Multi-choice survey instrument provided measures on 'alignment' of service managers to perspective and values to corporate directions. The multichoice approach conveniently lists 'options' relating to corporate values with an 'other' option choice enabling diversity. This approach enabled the interviewer to quickly introduce the Multi-choice instrument; which in-turn enabled the respondent to quickly contextualise the questions by viewing the range of options.

A simple survey of income, expenses and staff distribution provided an indicative view on resource distributions in terms of service areas, compared with under-resourced frontline services (hot-spots) or services with potential to mitigate activity (risk-spots) that can lead to contractual disputes or building defects. Corporate (internal) support services appear to be well resourced to provide strategic support and direction to frontline services.

\subsection{Best Practice}

Demographic and commercial impacts are thought to be in a moderate transitional phase. Further, in transition are the introduction of new information technology platforms and applications. With limited potential for increasing income and resources, the recommended strategy of this study is to develop flexible applications with resources applied according to priorities that resolve operational issues.

For example, a more detailed resource distribution review should consider as a first priority services under external workload pressure (reactive hot-spots). Services with potential to mitigate external workload pressure (proactive risk-spots) are a 'second priority'.

As new technological systems are consolidated and service operations streamlined, operational-review resources can be applied to performance interpretations and measures to provide an evidence-basis for understanding what is working, while reflecting on where the risks are.

Public awareness strategies can be developed on newly devised standardised performance measures to contribute to public confidence in new building and private expectation of the responsibilities of parties through private building contractual processes.

\subsection{Conceptual Frameworks}

A key concept of this study is to view services through 
customer lenses, 'stepping into their shoes' [28, 29], by grouping customers by their characteristics such as: public confidence, private expectation, and frontline service needs.

An important recommendation in an environment of 'transition', with limited resources, is to take a conservative interpretation on the scope of the building control jurisdiction. To focus limited resources on services that are 'in the pubic pest interest', while raising public awareness on the business service model.

Further by providing customers with information to 'reality-test' private expectations on the roles and responsibilities of private parties to their building contract building owners and principle contractors may be better informed throuth awareness education to avoid disputes through better communication and understanding.

Promoting collaborative and cooperative behaviour between parties to the contract is better than focusing on legal hierarchies imposed through traditional contractual agreements [30, 31, 32]. A public view of an equitable approach, from Abrahamson's risk management principle [33, as quoted in 30] for example may be -

"Project risks are assumed by the party most capable of managing or controlling the risk: should no party be capable of managing a risk, then the client takes responsibility for this risk."

\section{Acknowledgements}

This project is inspired and guided by the Building and Construction Commission (QBCC) and the Board (QBCB). The acting commissioner kindly perused the paper offering valuable advice. Mr Paul Tilley's guidance is certainly appreciated, lecturer of construction management, Faculty of Health, Engineering and Science, of the University of Southern Queensland. Finally, thirty one service managers responded to the survey proactively, with interest.

\section{References}

1. Kim Hawtrey, pers. comm., 8 September 2015.

2. BIS Shrapnel, 2015, 'Building in Australia, 20152030; Building Forecasting', 35th Ed., July, pp. 302 [paper]

3. QBCC, 2015a, 'Annual Report 2014-2015', $<$ http://www.qbcc.qld.gov.au/sites/default/files/QBC C_Annual_Report_-_1Dec13_-_30Jun14.pdf $>$

4. Hope, P. G., 2015, 'QBCC 2014-15 dispute resolution service review of high-density residential building work', July.

5. Australian Government, 2015, $<$ http://www.business.gov.au/businesstopics/business-structures-and-types/industryfactsheets/Pages/national-construction-code.aspx $>$

6. QBCC Act 1991, 2015, pt. 1 (3), Queensland Government, $<$ https://www.legislation.qld.gov.au/LEGISLTN/CU RRENT/Q/QldBuildConCommA91.pdf>

7. QBCC 2015d, 'DNA Sheet', (internal document)
8. QBCC, 2015c, 'Corporate Plan 2015 - 2019; for peace of mind',

$<$ https://www.qbcc.qld.gov.au/sites/default/files/QB CC_Corporate_Plan_2015-2019.pdf $>$

9. QBCC, 2015b, 'License Classes', http://www.qbcc.qld.gov.au/when-you-needlicence/licence-classes

10. Georgiou, J., Smith, J., and Love, P. E. D., 2002a, 'Defects and quality control in the housing industry: Implications for management and regulatory control,' Proc., 8th Int. Conf. on ISO 9000 \& TQM (Change Management) CD-ROM, Centre for Management Quality Research, CMQR, at RMIT Univ., RMIT Storey Hall, Melbourne, Australia.

11. Smith, J., Mills, A., and Iyer-Raniga, U., 2004, 'Benchmarking the implementation of continuing professional development in the Victorian construction industry', Benchmarking CPD, FABP, UM, Building Commission, Victoria.

12. Brennan, B., 1990, 'Continuing Professional Education', Australian Council for Educational Research, Canberra.

13. DISR, 1999, 'Building for Growth: An Analysis of the Australian Building and Construction Industries (Competitive Australia)', Department of Industry, Science and Resources, Commonwealth of Australia, Canberra.

14. Ilozor, B., Okoroh, M. I., and Egbu, C. E., 2004, 'Understanding residential house defects in Australia from the State of Victoria,' Build. Environ, 39, 327-337.

15. Mills, A., Love, P. E. D., and Williams, P., 2009, 'Defect costs in residential construction', Journal of Construction Engineering and Management, ASCE, January.

16. ASIC 2015, 'Insolvency statistics summary', September quarter, $<$ http://download.asic.gov.au/media/3446712/insolv ency-statistics-summary-september-quarter-2015published-10-november-2015.pdf>

17. Georgiou, J., Love, P. E. D., and Smith, J., 1999, 'A comparison of defects in houses constructed by owners and registered builders in the Australian State of Victoria', Manage. Int. Rev., 17, 3, 160170 .

18. Georgiou, J., Smith, J., and Love, P. E. D., 2002b, 'Quality improvement through builder registration,' Proc., 8th Int. Conf. on ISO 9000 \& TQM (Change Management), CD-ROM, Centre for Management Quality Research, CMQR, at RMIT Univ., RMIT Storey Hall, Melbourne, Australia.

19. CRC CI, 2009, 'Guide to leading practice for dispute avoidance and resolution, $<$ http://www.constructioninnovation.info/images/pdfs/DAR_Guide.pdf $>$

20. ABS 2013, 8772.0, Private sector construction industry, Australia, 2011-12,

$<$ http://www.abs.gov.au/ausstats/abs@.nsf/Latestpro ducts/8772.0Main\%20Features2201112?opendocument>

21. CPSISC, 2014, p. 19, 'Environmental Scan 2014-15, Construction and Property Services Industry Skills 
Council, pp. 76. (e.g. Construction and Property Services Market) [paper].

22. Hope, P. G., 2014, 'Environmental Scan 2014-15', QBCC (internal document) pp. 76.

23. RBA, 2015, 'Minutes of the Monetary Policy Meeting of the Reserve Bank Board', Sydney, 4 August.

24. Queensland Treasury, 2015, 'Queensland population counter', 24 September, $<$ http://www.qgso.qld.gov.au/products/reports/popgrowth-qld/qld-pop-counter.php>

25. King, D., and Macgregor, C., 2000, 'Using social indicators to measure community vulnerability to natural hazards', Australian Journal of Emergency Management, 15 (3). pp. 52-57.

26. Fenton, D.M., and Macgregor, C., 1999, 'Framework and Review of Capacity and Motivation for Change to Sustainable Management Practices', theme 6: Project 6.2.1., Social Sciences Centre, Bureau of Rural Sciences, Canberra.

27. Treasury, 2014, 'Treasury Annual Report 2013-14', Australian Government, 31 October, $<$ http://www.treasury.gov.au/PublicationsAndMedia /Publications/2014/Treasury-Annual-Report-2013$14>$.

28. Cox, A., and Townsend, M., 1998, 'Strategic Procurement in Construction, Thomas Telford, London.

29. Comptroller and Auditor General, 2001, 'Modernising Construction', National Audit Office, London.

30. Tilley, P. A. 2005, 'Relationship contracting: a strategy for improved project performance', SCRI, University of Salford, UK.

31. Crow, T., 1998, 'Trust and trustworthiness', Paper delivered at the International Conference on TQM in Construction, Singapore.

32. Crow, T., and Barda, P., 2001, 'Projects as wealth creators; drivers of project excellence', Property Council of Australia, Sydney.

33. Abrahamson, M., 1982, 'Risk management', Paper presented at the International Construction Law Conference (19-21 October), Sydney. 